DOT/FAA/AM-10/18

Office of Aerospace Medicine

Washington, DC 20591

\title{
U.S. Airline Transport Pilot International Flight Language Experiences, Report 5: Language Experiences in Native English-Speaking Airspace/Airports
}

O. Veronika Prinzo

Civil Aerospace Medical Institute Federal Aviation Administration Oklahoma City, OK 73125

Alan Campbell Johns Creek, GA 30022

Alfred M. Hendrix and Ruby Hendrix HCS Consulting Services

Roswell, NM 88201

December 2010

Final Report 


\section{NOTICE}

This document is disseminated under the sponsorship of the U.S. Department of Transportation in the interest of information exchange. The United States Government assumes no liability for the contents thereof.

This publication and all Office of Aerospace Medicine technical reports are available in full-text from the Civil Aerospace Medical Institute's publications Web site: www.faa.gov/library/reports/medical/oamtechreports 
Technical Report Documentation Page

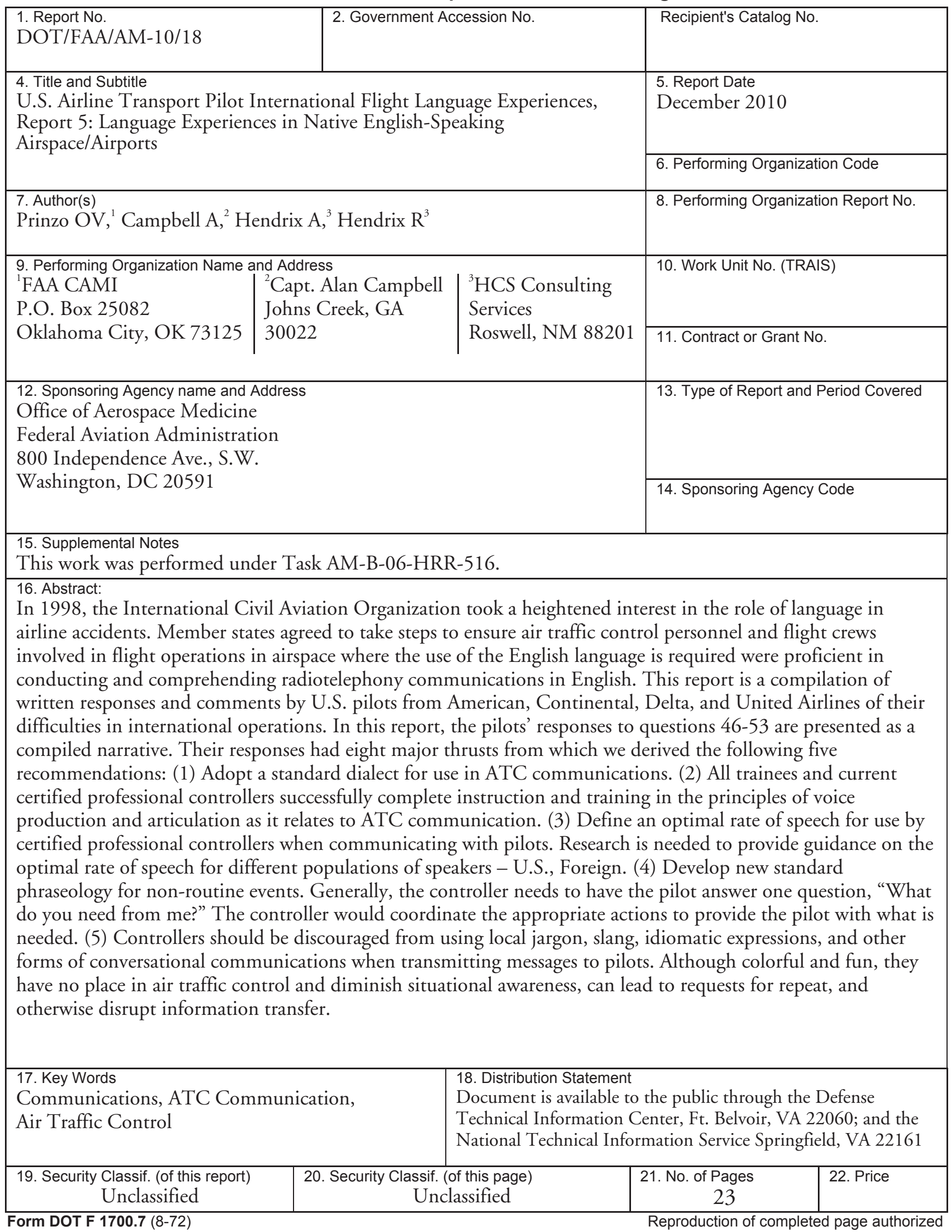





\section{ACKNOWLEDGMENTS}

This research was sponsored by the Federal Aviation Administration Flight Technologies and Procedures Branch under the direction of William Adams (AFS-430), and the findings were provided to the Data Com Human Factors Working Group. It was conducted under the Flight Deck Program Directive / Level of Effort Agreement between the Human Factors Research and Engineering Group (AJP-61), FAA Headquarters, and the Aerospace Human Factors Division (AAM-500) of the Civil Aerospace Medical Institute. We thank all the people at American, Continental, Delta, and United Airlines who were instrumental in the success of this project-especially the 48 U.S. pilots who participated in the interviews. Among these pilots were several who participated in the discussions either shortly after returning from international flights, left immediately after the interview to be part of international flight crews, or deadheaded to the company office from other states. These pilots exhibited passion for aviation safety and knew the importance their knowledge and expertise held in international flight operations. We cannot thank them enough. We also thank Captain Terry Hanson (retired) and Mr. Graham Elliott (AMA-800) for their helpful comments and items for inclusion in the interview questions. Finally, we thank the staff at Xyant Technologies for transcribing the many hours of voice tapes and written responses into Excel $^{\circledR}$ spreadsheets. 



\section{CONTENTS}

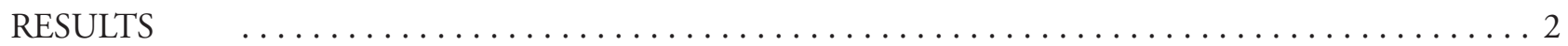

Section 7: Language Experiences in Native English-Speaking Airspace/Airports . . . . . . . . . . . 2

Q46. List the different native English languages you typically hear over your communications system

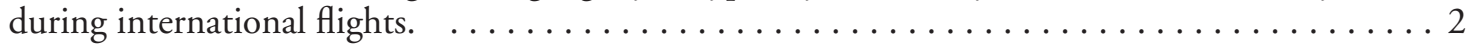

Q47. How would you rate your overall native English-speaking language experiences during

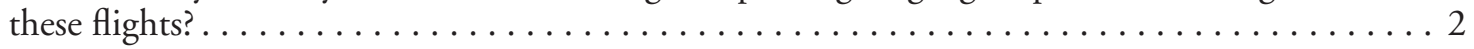

Q48. How is your workload affected by your experience with native English-speaking language differences during a flight? . . . . . . . . . . . . . . . . . . . . . . 2

Q49. How often do you experience communication problems in native English-speaking

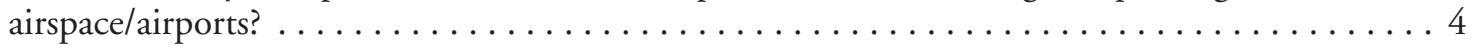

Q50. Of the native English-speaking airports that you fly to, do you find the English language skills of other pilots and controllers comparable? Please explain. . . . . . . . . . . . . . . 4

Q50a. Do you find that the intelligibility of some native English-speaking controllers' speech causes

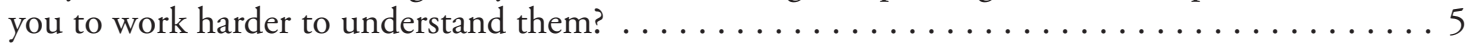

Q50b. What makes some international native English-speaking controllers' speech more difficult to

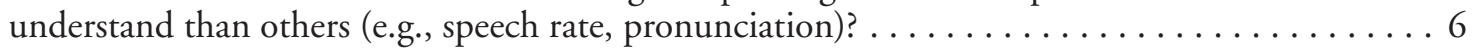

Q51. When flying in a native English-speaking country, how often do controllers use ICAO standard

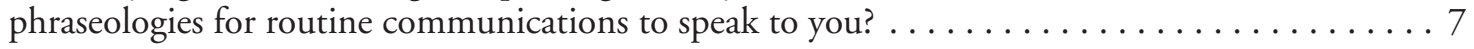

Q52. When flying in a native English-speaking country, how often do controllers use Common English for routine communications to speak to you? $\ldots \ldots \ldots \ldots \ldots \ldots \ldots \ldots \ldots$

Q53. When flying in a native English-speaking country, how would you describe the controllers' ability to communicate with you in Common English? . . . . . . . . . . . . . . 9

Q53a. In general, how much attention do you have to use to make sense of what the native English-

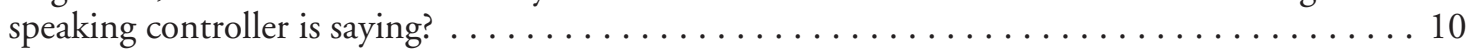

Q53b. What are the most troubling language-based problems you experience with native

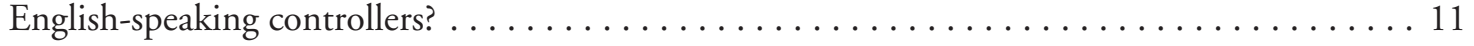

Q53c. How often have you heard native English-speaking controllers use jargon or slang that was

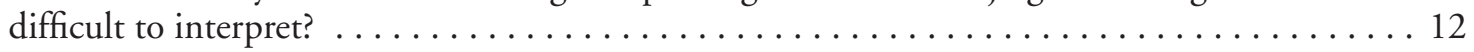

Q53ci. The respondents' examples of jargon that were difficult to interpret were "Guppy" and

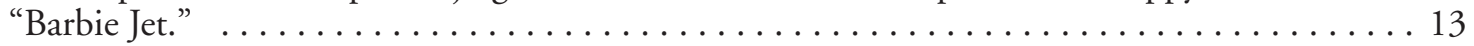

Q53cii. The respondents did not list any examples of slang that were difficult to interpret....... 13

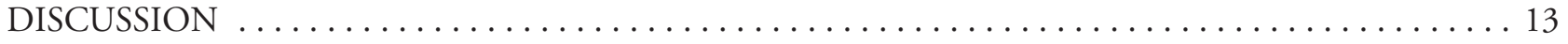

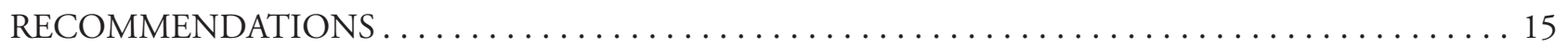

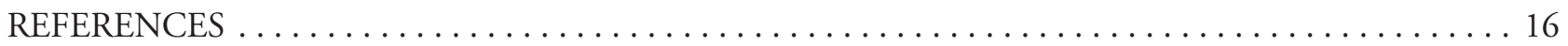





\section{EXECUTIVE SUMMARY}

This is the fifth report from Series One that presents the findings from in-depth interviews with U.S. pilots who fly internationally for major U.S. air carriers. The first series of reports are from small focus group discussions with U.S. air transport certificated pilots. A second series used the same format and questions with pilots flying internationally for Aeroflot, Alitalia, China Air, and LAN Chile airlines.

English language proficiency is a safety concern as noted by the International Civil Aviation Organization (ICAO 2004). Given that international flight operations are increasing, it is important to know more about the language experiences U.S. pilots encounter when flying into countries where English may or may not be the local or national language among their radio operators, air traffic controllers, and pilots.

Several major U.S. airline companies were asked to solicit volunteers from among their international pilots to serve as paid subject matter experts in a structured interview constructed to assess the language difficulties they encounter during international flights. There were 12 pilots each representing American, Continental, Delta, and United Airlines for a total of 48 airline transport pilots (ATPs). These pilots were assumed to be representative of typical U.S. airline pilots flying internationally as to English language proficiency, familiarity with ICAO and aviation procedures, terminology, and standard air traffic phraseology. We limited the size of each interview to include no more than four pilots. There were morning and afternoon sessions that took place over several days at each company's preferred location.

The structured interview was divided into 10 sections: (1) Background Information, (2) Pre-Flight Preparation, (3) Air Traffic Control (ATC) Procedures, (4) Word Meaning and Pronunciation , (5) Language Experiences in Non-Native English-Speaking Airspace/Airports, (6) Non-Native English-Speaking Controllers Communicating With Native English-Speaking Pilots, (7) Language Experiences in Native English-Speaking Airspace/Airports, (8) Native English-Speaking Controllers Communicating with Non-Native English-Speaking Pilots, (9) Communication Problems, and (10) Technological Intervention. A copy of the interview questions appears in the first report (Prinzo \& Campbell, 2008).

This report continues with the U.S. pilots' responses to questions found in Section 7. It provides a wealth of information related to their flight experiences when communicating with native English-speaking controllers. It provides an overall description of how these communication exchanges affected their perceptions of safety, communications, workload, and situational awareness.

The pilots' answers to the questions and discussions during the interviews were their perception of the situations they encountered. Many stories were anecdotal, and some were relayed in third person. The analyses of those discussions and written responses are summarized and presented as if from one pilot's diary containing a compendium of flight experiences. This was done to preserve the richness and integrity of the information given during the interviews.

When asked how hearing English spoken by a native English speaker affected their workload, 9\% of the pilots said they experienced decreased workload, $17 \%$ reported no change, $63 \%$ said there was only a minimal or slight increase, and $11 \%$ said workload increased. Among the pilots who reported a slight or minimal increase in workload, they attributed it to a more relaxed radio discipline and faster speech rate-especially when traffic was heavy. Another question asked how often they experienced communication problems, to which $94 \%$ of them said that it occurred in fewer than $25 \%$ of their interactions with controllers. If they did have a problem, it was corrected easily because English was the language they had in common. After being asked if native English language skills were geographically comparable, $83 \%$ of the pilots reported that the pilots and controllers were similar, while $17 \%$ said they differed (controllers had less of an accent). Although 90\% of the pilots perceived controllers as having good ( $47 \%)$ to excellent (52\%) communication skills, $75 \%$ said they used extra effort when listening to some native Englishspeaking controllers. Finally, native English-speaking controllers typically used ICAO phraseology in at least $75 \%$ of their routine communications, and the pilots seemed to be very positive about the controllers' use of Common English.

The pilots' responses were compiled into eight key issues:

1. For pilots and controllers alike (regardless of their country of origin or aircraft registry), some English dialects and accents are more difficult to understand, add workload, and require more of the listeners' attention be directed towards what is being heard. In addition to accents, regional differences in the pronunciation of a waypoint or fix made understanding the names difficult. This is especially so for new pilots (and controllers) who are unfamiliar with the accent and dialect or if the quality of the radio transmission/equipment is poor.

Understanding was particularly affected by differences in pronunciation, speech rate, and accent, followed by pitch, expectation, intonation, and phraseology. Some accents were easier to understand, while the ones unfamiliar to the pilots were said to be more difficult. Likewise with intonation, since it provides the emphasis, tone, variety in oral languages that can alter meaning by simply modulating pitch and loudness while speaking. Different English dialects have different intonation patterns that can affect how well listeners understand what is being said. 
2. Some controllers delivered clearances too fast, rendering some transmissions unintelligible. When the fast pace marries up with individual differences in accent and dialect, pilots pay more attention, especially if there are procedural differences they must be aware of. For example, a pilot from New York may have some problems understanding controllers from Georgia or Florida and visa versa, as would a pilot from Texas flying into Hong Kong or London.

When pilots and controllers do not understand each other due to these differences, coupled with rapid-fire speech, inevitably one or the other will make a request for repetition, confirmation, or verification, resulting in increased workload and radio frequency congestion.

Although \$5.2.1.5.3 of Annex 10 Volume II (ICAO, 2001) states that pilots "should maintain an even rate of speech not exceeding 100 words per minute," FAA Order 7110.10U Flight Services \$2-1-2 (FAA, 2010a) states weather and flight information and other information shall be broadcast/recorded as follows, "Data shall be spoken at a rate of 100 to 120 words-per-minute." However, there is no guidance in FAA Order 7110.65T Air Traffic Control (FAA, 2010b) for a specified speech rate air traffic controllers are to use when communicating with pilots. Generally, normal conversational speech occurs at about 160 words per minute (wpm) and depends, in part, on the number and duration of pauses and syllables (e.g., it takes less time to pronounce hat than hippopotamus).

3. The sampled U.S. pilots would like to see the U.S. adopt the ICAO standard. ATC telephony consists of a standard phraseology that controllers repeat throughout their workday. The pilots noted some controllers in the U.S. are more prone to use "Americanisms." Since there is a common language among the various English dialects, none of the U.S. pilots reported problems with any particular local slang or jargon. Slang, like idioms, appears in conversational speech and can be difficult for listeners who are unfamiliar with local expressions (or history) to understand, but they can work through them because of the common root language.

4. In the U.S., a standard phraseology was constructed for the advisories and separation of aircraft. There is no prescribed phraseology for communication concerning occurrences outside of clearances, advisories, and weather. Pilots and controllers communicate in Common English to convey information concerning accidents, emergencies, courtesies, etc.

5. The most troubling language-barrier problems with native English-speaking controllers are procedural issues, local knowledge, and not realizing that there might be differences between international and domestic ATC phraseology. The pilots provided examples of these differences-line up and wait (non-U.S.) compared to taxi into position and hold (U.S.) and the various meanings of direct routes: "direct," "direct to," "direct to (point) as filed," and "direct to (point) (airway/jet route)." The pilots seemed to prefer "present position direct to (point)."

6. Radio discipline varied with the degree of familiarity between the flight crew and controllers. As they gained familiarity with each other because of their common flight/work schedules, they recognized each others' voices. Communications could become more relaxed and conversational while maintaining a degree of professionalism.

7. The most troubling language-based problems centered on receiving more information in a single transmission than could be processed reasonably in the amount of time used to deliver it. Prinzo, Hendrix, and Hendrix (2009) found that long messages lead to substitution and transposition errors as pilots read back the message contents. One pilot provided the following example: "Climb to two two zero, heading one eight zero, slow up to two ten and proceed to GIPSO." It contains four instructions (altitude, heading, speed, and route). Likewise, complex messages (such as route clearances) lead pilots to omit portions during readback.

Finally, we present five recommendations derived from the pilots' responses to the interview questions and discussions. They are:

1. Adopt a standard dialect for use in ATC communications. Just as radio and television news broadcasters learn to speak using a nondescript accent, actors often hire language coaches to teach them the "standard Hollywood accent" to portray geographically neutral characters.

2. All trainees, current certified professional controllers, and pilots should successfully complete instruction and training in the principles of voice production and articulation as it relates to ATC communication.

3. Define an optimal rate of speech for use by certified professional controllers when communicating with pilots. Research is needed to provide guidance on the optimal rate of speech for different populations of speakers-U.S., Foreign.

4. Develop new standard phraseology for non-routine events. Generally, the controller needs to have the pilot answer one question, "What do you need from me?" The controller would coordinate the appropriate actions to provide the pilot with what is needed.

5. Controllers should be discouraged from using local jargon, slang, idiomatic expressions, and other forms of conversational communications when transmitting messages to pilots. Although colorful and fun, colloquial expressions have no place in air traffic control, diminish situational awareness, can lead to repeated requests, and otherwise disrupt information transfer. 


\title{
United States Airline Transport Pilot International Flight Language Experiences, Report 5: Language Experiences in Native English-Speaking AirSPace/Airports
}

\author{
Viewed freely, the English language is the accretion and growth of every dialect, race, \\ and range of time and is both the free and compacted composition of all. \\ — Walt Whitman, 1892
}

This is the fifth in a series of reports derived from the responses made by 48 U.S. pilots about their international flight experiences during structured, small focus-group interviews. The purpose of the interviews was to identify language issues that can become barriers to efficient and effective communication between airline transport pilots and air traffic controllers (who may or may not be fluent in English).

The first report (Prinzo \& Campbell, 2008) analyzed the first three sections of the structured interview: 1) Background Information related to the recency of international flight experiences among the pilot-participants; 2) General/ Preflight Preparation; and 3) Air Traffic Control (ATC) Procedures. It covered the U.S. pilots' responses and discussions of questions 1-23. The second report (Prinzo, Campbell, Hendrix, \& Hendrix, 2010a) continued with U.S. pilots' flight experiences when word meanings and pronunciation became barriers to efficient and effective communication. It covered the pilots' responses and discussions to questions 24-30 in Section 4. The third report (Prinzo, Campbell, Hendrix, \& Hendrix, 2010b) involved pilots' responses and discussions of questions 31-38 found in Section 5. It addressed their language experiences in non-native English-speaking airspace and airports. The fourth (Prinzo, Campbell, Hendrix, \& Hendrix, 2010c) continued with Section 6 (questions 39-45) and asked them about their language experiences with controllers who spoke English as a foreign language.

The questions in this report are from Section 7 of the interview and parallel those in the third report; they differ only in location: Report 3 probed pilots' language experiences in non-native English-speaking airspace and airports, while this report probes their language experiences in native English-speaking airspace and airports. Regardless of location, controllers must communicate in English with foreign pilots. Thus, U.S. pilots were able to reflect upon their experiences flying in both English and non-English speaking-countries.

Language is a means of communicating systematically by the use of sensory systems (e.g., sight, sound, touch) to convey meaning and express thoughts. It has common linguistic features that make its properties intelligible among people who share that language. English is the dominant language of the United Kingdom (U.K), the United States (U.S.), Canada, the Republic of Ireland, Australia, New Zealand, and a number of other countries; however, it is spoken in many different dialects.
Dialect refers to the variation among some linguistic features that set it off from other varieties within that language. Dialects may differ in vocabulary, grammar, and pronunciation. For example, regional dialects in the U.S. may differ in vocabulary, grammar, and pronunciation. As noted by Leverett (2007), New Yorkers may refer to a group of their friends as "youse," while natives of Pittsburgh might address this same group as "you'ns." Southerners might say "y'all" or "all-of-y'all," and Midwesterners, "you guys," (regardless of the group's gender).

People unfamiliar with regional expressions would have difficulty understanding a local speaker since the relationship between an expression and its meaning can be geographically unique. For example, a visitor to Akron, Ohio, might not understand what the sign in Figure 1 meant. Once told that the strip of land separating the street's curb from the sidewalk is called the "devil strip" (Cassidy \& Hall, 1991), the sign becomes meaningful.

As entertaining as it might be to find (or experience) regional variations, they can cause difficulty in ATC communication. Like visitors to Akron, Ohio who might not know about the "devil strip," pilots might experience similar difficulties due to differences among dialects. The pilots who participated in this study were instructed to think about how hearing other native dialects of the English language affected their safety and communications between them and air traffic controllers.

As with the other reports in this series, the pilots' oral responses were combined, condensed, and edited to remove redundancies and improve readability. Each report was presented from the perspective of a hypothetical, albeit typical Airline Transport Pilot (ATP) certificated pilot. When possible, the content was tabulated and presented in tables. If their responses to a particular question appeared to address similar topics with an underlying issue or concern, they were grouped together and its core issue, or concern, was extracted and labeled. 


\section{RESULTS}

\section{Section 7: Language Experiences in Native English-} Speaking Airspace/Airports

The questions in this section of the interview focus on how hearing other dialects of the English language affected safety and communication between the pilot and air traffic controllers.

\section{List the different native English languages you typically} hear over your communications system during international flights (e.g., North American English, Australian English, British English, Hong Kong English, Indian English).

As shown in Table 1, the pilots listed 17 different dialects of the English language. Of these dialects, British English appeared in 26\% of their 128 total responses. Likewise, they listed North American English in 21\% of their responses and Hong Kong English in approximately $8 \%$ of their responses.

\section{How wouldyou rate your overall native English-speaking language experiences during these flights?}

A compilation of the pilots' responses revealed that approximately $79 \%$ rated their English language experiences as either "Very positive" (17) or "Positive" (21). Eight pilots provided a rating of "Neutral," one gave a rating of "Negative," and one gave a rating of "Positive/ Negative" (Mixed).

\section{Positive Explanation}

Of the four respondents who offered comments, the most common theme was that even though dialects vary, understanding is easier when the participants share the same language.

\section{Same Language, Different Accents}

Even though some of the accents may be a little bit more difficult for me, the words are the same, and that makes understanding the meaning easier. Because we speak the same language, we can slow down and still convey the point. We can enunciate more clearly if necessary to clarify a situation or if we don't understand one another. We cannot do that when we're speaking different languages because there's no common baseline.

\section{Neutral Explanation}

To all eight of the pilots who selected "Neutral," some dialects seemed peculiar, but the problems they experienced didn't necessarily result from these dialects.

\section{Negative Explanation}

One pilot provided a negative explanation. For him, not all English dialects are easy to understand.

\section{Native English Speakers Don't Receive Speech Training}

I think some non-native English-speaking controllers probably receive training on how to limit their accent and dialect issues. My guess is that a controller from an English-speaking country doesn't receive similar training. So, when he speaks, that's the English we hear, even though the accent and dialect might make it difficult for us to understand.

\section{How is your workload affected by your experience with native English-speaking language differences during a flight?}

To avoid biasing pilots' responses, this question was written such that workload could remain the same, increase, or decrease. We attempted to compile their individual responses according to commonalities. In most cases, it was easy. When otherwise, it required judgment derived from the pilot's written and oral responses. Table 2 shows $71 \%$ of the pilots qualified their responses by stating that traffic volume, experience, and differences in dialects (just to name a few) had to be taken into consideration.

Table 1. Dialects of English Heard by U.S. Pilots During Their International Flights.

\begin{tabular}{|l|c|c|c|c|c|}
\hline $\begin{array}{c}\text { Continent/Geographic } \\
\text { Region/Dialect }\end{array}$ & $\begin{array}{c}\text { Number of } \\
\text { Responses }\end{array}$ & $\%$ & $\begin{array}{c}\text { Continent/Geographic } \\
\text { Region/Dialect }\end{array}$ & $\begin{array}{c}\text { Number of } \\
\text { Responses }\end{array}$ & $\%$ \\
\hline Asia & 2 & 2 & North America & & \\
\hline Chinese/Taiwanese & 10 & 8 & Island English & 2 & 2 \\
\hline Hong Kong & 7 & 5 & Belize/Jamaica & 3 & 2 \\
\hline India English & & & $\begin{array}{c}\text { British West } \\
\text { Indies/Jamaica }\end{array}$ & 1 & 1 \\
\hline Europe & 5 & 4 & Bermuda & 1 & 1 \\
\hline United Kingdom & 33 & 26 & North American English & 27 & 21 \\
\hline British English & 7 & 5 & Canadian English & 8 & 6 \\
\hline Irish & 8 & 6 & U.S.A & 3 & 2 \\
\hline Scottish & & & Oceania & & \\
\hline & & & Australian & 6 & 5 \\
\hline & & & New Zealand & 2 & 2 \\
\hline
\end{tabular}

a. A geographical area in the Pacific consisting of Australia, New Zealand, and surrounding islands. 
Table 2. Effects of Native English Language Experiences on Pilot Workload.

\begin{tabular}{|c|c|c|c|}
\hline Outcome on Pilot Workload & $\begin{array}{l}\text { Number of } \\
\text { Pilots }\end{array}$ & $\%$ & Common Thread \\
\hline No Change & 8 & 17 & Hearing Different Dialects Has No Impact \\
\hline Decrease & 4 & 8 & We Speak the Same English Language, Just Differently \\
\hline Minimal Increase & 13 & 27 & $\begin{array}{l}\text { Non-Standard Communications Occur More Frequently; } \\
\text { Some Areas Are Fast Paced Due to Traffic Volume }\end{array}$ \\
\hline $\begin{array}{l}\text { Minimal Increase With } \\
\text { Qualifications }\end{array}$ & 7 & 15 & $\begin{array}{l}\text { New Crewmembers Have a Harder Time Understanding; } \\
\text { Pilots Have Difficulty Understanding Some Dialects; } \\
\text { Poor Radio Quality Coupled With Different Dialects }\end{array}$ \\
\hline Slight Increase & 9 & 19 & $\begin{array}{l}\text { Pilots Have Difficulty Understanding Some Dialects; } \\
\text { Differences in ICAO Terminologies }\end{array}$ \\
\hline Increase With Qualifications & 5 & 10 & Hearing Different Dialects Has an Impact \\
\hline No Response & 2 & 4 & \\
\hline
\end{tabular}

\section{No Change Explanation}

The eight pilots in this group indicated that hearing different English dialects had no impact on their workload. Nothing was offered beyond their written comments of no real difference or negative effect.

\section{Decreased Workload Explanation}

Four respondents reported that English was easier to understand and always standard. Three of the pilots offered comments during the interviews.

\section{We Speak the Same English Language, Just Differently}

When we leave Europe and are told to contact London control, I feel a little weight come off my shoulders. My workload is definitely reduced and it's just easier, even though some of the English dialects may be difficult for me to understand. We may have to ask to have it said again, but we can always figure out what is being said because we have that common language to fall back on.

\section{Minimal Increase in Workload Explanation}

Thirteen respondents reported that their workload increased in some regards. During the discussions, 38\% provided comments. Generally, the increase was minimal, with less concentration required, and controllers were easily understood.

\section{Non-Standard Communications Occur More Frequently}

For me, understanding is the work, and since I don't find English [dialects] to be real different, it's easy to understand so it doesn't create an issue. One thing that does crop up in native English-speaking areas is a tendency to use more pleasantries, jargon, and chitchat. We may not catch all of it and it's not a big deal, but we have to really listen.

\section{Some Areas Are Fast-Paced Due to Traffic Volume}

Sometimes my concern is with speed of communication. There are places with lots of traffic moving rapidly — like the Northeast Corridor or Chicago. Our workload goes up because we have to listen specifically for our call sign since we rarely get a chance to do a repeat or verification of the clearance. It does not matter whether the controller is a native or nonEnglish speaker; if we didn't understand or hear the correct words, we need to make sure that what we think was said is what was said.

\section{Minimal Increase With Qualifications Explanation}

Seven respondents reported their workload increased, but they qualified their responses. An examination of their written comments indicated that accents played a role, as did the experience level of the flight crew. During the interviews, $57 \%$ of these pilots provided additional comments.

\section{New Crewmembers Have a Harder Time Understanding}

It's not much of an effect, unless we have a new crewmember that may be having difficulty with the language changes, even though it's English. Now there's no back up; it's a threat because I'm the only one hearing.

\section{Pilots Have Difficulty Understanding Some Dialects}

I don't think it has that big of an impact although, sometimes it's hard to understand particular dialects. The native English-speaking language differences are usually easily resolved. If you ask, they make sure you understand what they want you to do.

\section{Poor Radio Quality Coupled With Different Dialects}

I'm sure it's the radio because we probably sound like that to them over their receivers. For me, Scottish control is difficult because I have a hard time with their thick brogue, especially when their radios make them sound like they're talking from the bottom of a deep well. The only radios that are worse are in some areas in South America.

\section{Slight Increase Explanation}

Of the respondents who reported their workload increased, $78 \%$ provided comments during the discussions. For this group, the pilots reported difficulty understanding accented-English dialects. 
Table 3. Pilot Reports of Communication Problems Experienced in Native English-Speaking Airspace/Airports.

\begin{tabular}{|l|c|c|c|}
\hline \multicolumn{1}{|c|}{ Alternative } & Number of Pilots & $\%$ & \multicolumn{1}{c|}{ Issues } \\
\hline $\begin{array}{l}\text { Rarely } \\
(<10 \% \text { of my interactions with controllers) }\end{array}$ & 38 & 79 & Speech Rate and Accent \\
\hline $\begin{array}{l}\text { Occasionally } \\
(10-24 \% \text { of my interactions with controllers) }\end{array}$ & 7 & 15 & Phonetics Versus Fix Name \\
\hline $\begin{array}{l}\text { Frequently } \\
(25-74 \% \text { of my interactions with controllers) }\end{array}$ & 2 & 4 & The U.K.a and East Caribbean \\
\hline $\begin{array}{l}\text { Often } \\
\text { (75-90\% of my interactions with controllers) }\end{array}$ & 1 & 2 & LAX $_{b}$ Versus Dulles Dialect \\
\hline $\begin{array}{l}\text { Without Fail } \\
(>90 \% \text { of my interactions with controllers) }\end{array}$ & 0 & 0 & \\
\hline
\end{tabular}

aUnited Kingdom

bLos Angeles Airport located in California while Dulles is in Sterling, Virginia

Pilots Have Difficulty Understanding Some Dialects

Depending on where native English-speaking controllers are from, my workload goes up slightly when I'm listening to their accents. So, we anticipate what we're going to hear. Parts of the U.S. definitely have dialects—like the Deep South, Boston's airspace, or Houston-[and] differ from other areas. Also, my own native English-speaking environment is New York. They say we have an accent, but I don't hear it. To me it's no problem.

\section{Differences in ICAO Terminologies}

The difference would include the terminologies in ICAO communications.

Interviewer: So you're saying the ICAO differences increase your workload?

There is a little more workload. It's more proper [outside the U.S.] instead of the slang and the relaxed atmosphere that we enjoy domestically.

\section{Increase With Qualifications}

Five respondents reported their workload increased. Their written comments suggested they put forth more effort listening and interpreting what was said by controllers who spoke in different dialects. Sixty percent of the pilots provided comments.

\section{Hearing Different English Dialects Has an Impact}

In many ways, communication is the essence and probably the most critical function we do, other than fly the airplane. If nobody was around us, then it would not necessarily be a player. Sometimes English dialects increase my workload because I'm listening more intently to what's being conveyed. We have to be more careful with the local differences in what a word means, rather than how it is said.

\section{How often do you experience communication problems in native English-speaking airspacelairports?}

As seen in Table 3, 79\% of the pilots reported rarely having communication problems in native Englishspeaking airspace/airports. Another 15\% experienced an occasional communication problem. The comments from the pilots during the interviews are presented according to their response selection.

\section{Rarely Explanation}

Among this group of 38 pilots, $11 \%$ indicated that the problems they experienced were from clearances being given too quickly and in accents that were difficult for them to understand. However, the problems were cleared up quickly once the pilots indicated they did not grasp what was said.

\section{Occasionally Explanation}

Of the seven pilots who reported "Between 10-24\% of my interactions with controllers involve communication problems," only one provided comments. For that pilot, hearing the name of a fix was not always understood and required him to ask the controller to spell it.

\section{Frequently Explanation}

Both of the pilots circled "Frequently (between 25$74 \%$ of my interactions with controllers)" and provided comments during the interviews. One reported having difficulty in the U.K., whereas everything else was great. The other pilot had difficulty in the Eastern Caribbean, but it was not an issue in Canada.

\section{Often Explanation}

One pilot circled "Often (between 75-90\% of my interactions with controllers)." That pilot reported having problems understanding what controllers are saying when flying from Los Angeles to Dulles.

\section{Of the native English-speaking airports that you fy to, do you find the English language skills of other pilots and controllers comparable? Please explain.}

\section{Yes, They Generally Are Comparable}

Thirty-nine pilots reported that the English language skills of other pilots and controllers were comparable, of which half offered minimal, or no explanation. Of the pilots who did respond, they either heard little variation or had no problem communicating with controllers. 
Table 4. Frequency Pilots' Listed A Particular English Dialect As Being Difficult to Understand.

\begin{tabular}{|l|c|}
\hline \multicolumn{1}{|c|}{ Languages Mentioned } & Number of Times Listed \\
\hline Indian English & 7 \\
\hline U.K. English & 23 \\
\hline U.S. English & 10 \\
\hline Asian, Australian, Eastern Caribbean, New Zealand English & $1-2$ times each \\
\hline
\end{tabular}

For the pilots who commented and said that the pilots' and controllers' English-language skills were comparable, they also reported some differences. Their discussions centered on the importance of actively listening to what was spoken because of some subtle differences in accents, dialect, radio discipline, and differences between the U.S. and ICAO.

\section{Non-Native English Speakers in the Mix Change Everything}

Foreign carriers flying here and American carriers going to another country have the same problem-we have a hard time understanding what was said and ask to have the clearance repeated once or twice. We hear Aero Mexico, Air France, Korean Air, and other non-native English pilots asking for repeats because they often have a tough time understanding our controllers. The controllers' speak to them a little bit differently. ${ }^{1}$

\section{Northeast Corridor and Chicago Controllers Talk Fast}

The English language skills of other pilots and controllers are comparable, but in the Northeast Corridor and Chicago, bad weather tends to really get people talking a lot faster. I get the impression that controllers may be less tolerant if a pilot asks for a clearance to be repeated.

\section{The Larger Challenges Are the Differences Between the ICAO and U.S.}

There are a few problems. For example, confusion often exists in a single word but not [a] phrase. The Brits might say, "Your assignment is stand 15," versus "gate 15." But here, if we say stand, the controller might think we meant a hardstand,2 so we might not get a gate at all. It seems to me that U.S. controllers use more slang and less ICAO phraseology compared to the controllers outside the U.S. who are excellent; our own controllers could learn a thing or two about radio discipline.

\section{Workload Increases as English Dialect and Accents Differ}

The more a language, inflection, and dialect dif-

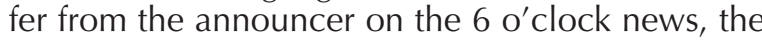
more my workload goes up. When that happens, it is important for me to listen carefully and transmit clearly. For me, the British accent in Scottish

\footnotetext{
${ }^{1}$ Prinzo \& Thomson's 2009 analysis of U.S. controller utterances transmitted only to non-native English Foreign registry aircraft.

${ }^{2} \mathrm{~A}$ hardstand is a hard-surfaced area for parking aircraft or ground vehicles.
}

airspace and the Scottish brogue can be difficult to understand, as is the accent in the Northeastern U.S.- - although controllers seem to have less of an accent than pilots do.

\section{No, They Generally Are Not Comparable}

Eight pilots reported that pilots and controllers were not comparable. Generally, this group mentioned where the problems were most notable. For them, it was pilots with poor English language skills who were less proficient.

I might get a great controller and then two bad ones-so each individual (and country) is different. London has probably the widest variety due to nearly every international carrier operating there. The native English-speaking pilots do fine, but some pilots from non-native English-speaking countries have limitations. They present very big problems for Los Angeles and San Francisco. I hear our controllers repeat messages over and over again while the pilots are trying unsuccessfully to read it back in English.

50a. Do you find that the intelligibility of some native English-speaking controllers' speech causes you to work harder to understand them? Use any examples that you may care to (e.g., Indian English, Hong Kong English, British English, North American English, U.S. regions where you might hear Mid-Atlantic English, North Central American English, Pacific Northwest English, Southern American English).

The pilot responses to this question were separated into two components. The first one involved their examples of places where they experienced difficulties due to intelligibility. The second involved aspects of speech, and it was moved to question $50 \mathrm{~b}$, where it was integrated with speech characteristics.

I Have to Work Harder to Understand What Was Said

Approximately $73 \%$ of the pilots reported that they worked harder to understand some native Englishspeaking controllers. They cited accent, jargon, pronunciation, and speech rate as primary factors affecting intelligibility. They provided some specific examples that reflected regional differences. As seen in Table 4, although a particular country might have been mentioned once or twice, the majority of the pilots limited their discussions to accents used in India, the U.K. (England, Northern Ireland, Scotland, and Wales), and the U.S. (New England, Southeast, and Southern regions). 
Table 5. Frequency Speech Factors That Make It Difficult to Understand Controllers.

\begin{tabular}{|l|c|}
\hline \multicolumn{1}{|c|}{ Speech Factors Affecting Understanding } & Number of Times Listed \\
\hline Accent & 16 \\
\hline Expectation & 2 \\
\hline Intonation & 2 \\
\hline Phraseology & 2 \\
\hline Pitch & 4 \\
\hline Pronunciation & 26 \\
\hline Speech rate & 23 \\
\hline
\end{tabular}

If It Is in English, We Can Work Out Any Problem

Although intelligibility causes us to work harder, we can always ask native English-speaking controllers what they meant, and they will understand us. There are some nuances among English speakers, and our accents and dialects are all a little bit different, but we're going to communicate and that overrides any problems we may have.

\section{Some Accents and Dialects Are Easier to Understand Than Others}

Each controller is different and I find some have really heavily-accented English. London has a wide variety of English dialects, since nearly every international carrier operates there. When I hear a thick South Hampton accent, it's harder for me to keep up with what's being said. For me, Welsh, Scottish, and Irish English can be difficult to understand because of the accent, as well as the Scottish and Irish dialects.

In the U.S., I hear Southern controllers slur their words, and the ones in the Southeast are more problematic than Boston or New York because I have difficulty understanding what they are asking me. Sometimes the Boston controllers use strange pronunciations.

\section{Some U.S. Controllers' Speech Rate Is Fast}

I notice that sometimes the controllers in New England talk too fast as do the New Yorkers. I've experienced New York Approach fire instructions nonstop, and I know they're not going to be happy if we miss one. When at $\mathrm{O}^{\prime}$ Hare, I perceive controllers as speaking like auctioneers, but I understand them. I think it would be difficult to operate in that environment as a foreign pilot.

\section{The Only Issue Is Jargon}

The work increase I experience is due to the use of jargon, as opposed to maintaining standard aviation communication terminology.

Interviewer: If you heard a controller tell you, go fast, how would you interpret that?

I expect it's probably maximum forward speed. It means fly as fast as you're willing to fly within the legal bounds of the airspace. If we're number one in line, we're to start getting everything going-ATC wants to increase separation so they're telling us to get going. But, it depends on where we are. If I'm over Houston at 35,000 feet, that's doable-it's10 knots below placard. If over San Juan, I'd ask him what he wanted me to do.

Interviewer: Another phrase that I heard is good rate down. How would you interpret it?

It would be the same interpretation. Increase your descent rate to the maximum you can.

Actually, another term that's quite frequently used is you're number one. It means you're holding everybody up. So, if you're planning on slowing down early, let ATC know. It also means we can go as fast as we like. We tend to want to go fast at lower altitudes to conserve fuel or make up time.

\section{Do Not Have to Work Harder to Understand}

Thirteen respondents indicated they had no increase in workload. They only experienced minor problems, but overall, the effects were insignificant.

The intelligibility of native English-speaking controllers does not usually make me work harder to understand them. I'm in North America, in my own world. I find a very minor problem down in the Islands-Antigua, Barbados, places like that where controllers use Island English. It's a [vulgaris vicus lingua $]^{3}$ where there may be several different pronunciations for the same word. For example, is it Cara(bee)an or $\mathrm{Ca}($ rib)ean?

\section{0b. Whatmakessome internationalnative English-speaking controllers' speech more difficult to understand than others (e.g., speech rate, pronunciation)?}

Forty-seven pilots listed the speech characteristics they thought made understanding controllers difficult for them. Sixty-eight percent provided oral comments. Of the 75 generated items, Table 5 shows pronunciation, speech rate, and accent appeared more frequently than pitch, expectation, intonation, or phraseology.

\section{Accents}

I find that some accents are more difficult to understand-especially unfamiliar ones. The more these accents differ from what I am used to, the more I experience a slight increase in workload and stress levels. I may need controllers to repeat some phrases (possible jargon issues), but I can ask what they meant and they will understand me.

\footnotetext{
${ }^{3}$ Vulgaris vicus lingua is simplified communication created by people of different languages so they can talk to each other. It can be a local, informal language "of the street" that evolves over time and generations.
} 
Table 6. How Often Controllers in a Native English-Speaking Country Use ICAO Standard Phraseology.

\begin{tabular}{|l|c|c|l|}
\hline \multicolumn{1}{|c|}{$\begin{array}{c}\text { How Often ICAO Phraseology Used for Routine } \\
\text { Communication }\end{array}$} & $\begin{array}{c}\text { Number } \\
\text { of Pilots }\end{array}$ & $\%$ & \multicolumn{1}{c|}{ Issues } \\
\hline $\begin{array}{l}\text { Without fail } \\
(>90 \% \text { of my interactions with controllers) }\end{array}$ & 19 & 40 & $\begin{array}{l}\text { United States, England, and Ireland Use } \\
\text { Standard ICAO; United States Uses Non- } \\
\text { Standard Phraseology and Should Change }\end{array}$ \\
\hline $\begin{array}{l}\text { Often } \\
(75-90 \% \text { of my interactions with controllers) }\end{array}$ & 22 & 46 & $\begin{array}{l}\text { United States' Use of ICAO Standards } \\
\text { Varies; Australia and Canada Stand Out For } \\
\text { Their Use of ICAO Standards }\end{array}$ \\
\hline $\begin{array}{l}\text { Frequently } \\
(25-74 \% \text { of my interactions with controllers) }\end{array}$ & 6 & 13 & \\
\hline $\begin{array}{l}\text { Occasionally } \\
\text { (10-24\% of my interactions with controllers) }\end{array}$ & 0 & 0 & \\
\hline $\begin{array}{l}\text { Rarely } \\
\text { (<10\% of my interactions with controllers) }\end{array}$ & 0 & 0 & \\
\hline No Response & 1 & 2 & \\
\hline
\end{tabular}

\section{Expectations and Assumptions}

You find some difficulty in your expectation of what you should hear. In other countries, controllers use phraseologies like line-up and wait. In the U.S., it's position hold. Just because we speak English doesn't mean we understand what was said.

\section{Intonation}

I find the lilt of the Indian English language hard to understand; I don't know what they want me to do. But, if I ask, they'll certainly come back with the answer I need. In particular, Hindi English is difficult for me.

Interviewer: When a pilot in your group said "Hindi," it seemed like it struck a nerve.

Well, I've made quite a few trips to Delhi and was unprepared for the particular cadence in their speech. It is actually fun to listen to until we have to know exactly what they're saying. If I could listen to it and not have to comply with anything, I'd be fine. Fortunately, my IRO ${ }^{4}$ had been there a number of times and said, "They mean this," or "they mean that." After three trips, I still don't understand what is being said.

\section{Pitch}

I'm really focusing in on high-pitched voices because it seems to me that the lower voices are, the easier it is for me to understand. I don't care if they are male or female.

\section{Pronunciation}

Although controllers may speak different English dialects, emphasis will be on different syllables"v(eye)tamins" versus "v(it)amins." Sometimes when words are slurred together, it's hard for me to determine exactly where words start and stop. It varies in the nation and with the controllers-it's almost like hearing a different language.

\footnotetext{
${ }^{4}$ International Relief Officer
}

\section{Speech Rate}

If communication was slow and deliberate-it would be easier to understand what was said for all the places we go.

\section{The Challenges Seasoned Pilots Experience Are No Longer Satisfying}

There are quite a few pilots who avoid flying to some parts of the world because of language concerns - they're afraid of miscommunication. This forces junior pilots with the least experience to fly into these sections. For me, that's a safety concern.

Rapid speech, nasal-sounding words, and some English dialects are a few of the difficulties I experience. The rigors of flying to Delhi or other destinations, going through Russia and all the "stans" to get there is professionally satisfying because it involves meters, QFE instead of QNH, ${ }^{5}$ different accents, and carbon microphones. But, I no longer want to be challenged in that way. So, I'm not going there anymore.

51. When flying in a native English-speaking country, how often do controllers use ICAO standard phraseologies for routine communications to speak to you?

As shown in Table 6, 46\% of the pilots reported controllers often use ICAO standard phraseologies for routine communication, while another $40 \%$ said it was without fail. Their comments are compiled according to their response selection.

\section{Without Fail Explanation}

Of the 19 pilots who selected "Without fail (more than $90 \%$ of my interactions with controllers)," $16 \%$ discussed their responses.

\section{United States, England, and Ireland Use Standard ICAO}

I thought about this for awhile, and I probably changed it a couple times. But, I really think we're

\footnotetext{
${ }^{5}$ Atmospheric Pressure (Q): QFE altimeter setting is the actual surface pressure, and it is not corrected to sea level. QNH is the barometric pressure as reported by a particular station.
} 
Table 7. Common English Usage By Native English-Speaking Controllers.

\begin{tabular}{|c|c|c|c|}
\hline Alternative & $\begin{array}{l}\text { Number } \\
\text { of Pilots }\end{array}$ & $\%$ & Issues \\
\hline $\begin{array}{l}\text { Without fail } \\
\text { (>90\% of my interactions with controllers) }\end{array}$ & 4 & 8 & \\
\hline $\begin{array}{l}\text { Often } \\
\text { ( } 75-90 \% \text { of my interactions with controllers) }\end{array}$ & 10 & 21 & $\begin{array}{l}\text { Pilot/Controller Familiarity Leads to Common } \\
\text { English } \\
\text { U.S. Controllers Do Not Use ICAO Terminology }\end{array}$ \\
\hline $\begin{array}{l}\text { Frequently } \\
\text { (25-74\% of my interactions with controllers) }\end{array}$ & 9 & 19 & $\begin{array}{l}\text { It Is Easier to Communicate in Your Native } \\
\text { Language }\end{array}$ \\
\hline $\begin{array}{l}\text { Occasionally } \\
\text { (10-24\% of my interactions with controllers) }\end{array}$ & 19 & 40 & $\begin{array}{l}\text { "Enter the Hold" and "Miles to Run" } \\
\text { "Ride Reports" and "General Weather" } \\
\text { Used With Domestic Carriers Only } \\
\text { U.S. Uses Common English More Than U.K., } \\
\text { Canada, or Australia }\end{array}$ \\
\hline $\begin{array}{l}\text { Rarely } \\
\text { (< } 10 \% \text { of my interactions with controllers) }\end{array}$ & 5 & 10 & No Time for Common English \\
\hline No Selection & 1 & 2 & \\
\hline
\end{tabular}

talking about the U.S. Most of the communications that I receive are pretty standard. There certainly is some jargon out there sometimes-but, for the most part in the United States, England, and Ireland, it is very standard for routine communications.

\section{United States Uses Non-standard Phraseology and Should Change}

It seems to me that both Canada and the U.S. use the Americanism; everywhere else uses standard ICAO. Our controllers are more prone to non-standard phraseology; other English-speaking countries use standard phraseology, at least on the first attempt.

Interviewer: Do you feel that the U.S. should get in line with the rest of the world, or do they need to get in line with us?

We should get in line with the rest of the world. It's a standard with ICAO.

\section{Often Explanation}

Approximately $27 \%$ of the 22 pilots who circled "Often (between $75-90 \%$ of my interactions with controllers)" elaborated upon their choice during the discussions.

\section{United States' Use of ICAO Standards Varies}

It's ICAO standard-what I'm used to in this country. The busier controllers get, the more they use the ICAO phraseology. The controllers chitchat when we have time for a conversation.

\section{Australia and Canada Stand Out For Their Use of ICAO Standards}

I was thinking Australia because I'm impressed by the way they try to stick with ICAO phraseology. I've found it to be the same in Canada. They'll correct us if we're not doing it right. If we come on and use the term heavy, they'll always come back and say it [as part of the call sign]. I think they work a lot harder at it than we do, and I like that.

\section{Frequently Explanation}

Of the six pilots who circled "Frequently (between $25-74 \%$ of my interactions with controllers)," two said they misunderstood the question and had nothing further to say.

52. When flying in a native English-speaking country, how often do controllers use Common English for routine communications to speak to you?

Common English, also known as International English, refers to the common properties shared among different dialects of the English language. Notably, they share a common subject-verb-object grammar, but differ in cultural expressions, word usage (pronunciation, spelling), and other characteristics (idioms, slang). Common English is used in global commerce. Common or plain English occurs when either the pilot or controller switches from standard phraseology and speaks in a conversational manner.

Table 7 shows the U.S. pilots reported controllers in native English-speaking countries use Common English to varying degrees when interacting with them. Approximately $40 \%$ indicated that controllers occasionally spoke to them in Common English, while another $40 \%$ indicated Common English was spoken either "Frequently" (19\%) or "Often" (21\%). Only 8\% said it was spoken "Without Fail." During the interviews, the one pilot who did not make a selection said,

Common English is what pilots and controllers revert to when ICAO standard phraseology doesn't work.

\section{Without Fail Explanation}

Although four pilots selected this response, only one commented.

I've found that international destinations use ICAO terminology for U.S. carriers even in native Englishspeaking countries. In return, Common English is expected to be used. 


\section{Often Explanation}

Of the 10 pilots who selected this response, 50\% discussed it during the interviews.

\section{Pilot/Controller Familiarity Leads to Common English \\ We do a lot of flying to Florida. We hear the same controllers and they hear us. We get to know them, even though we've never met. It's like talking to a friend rather than some unknown person behind the radio. There is an "ease of communication" with a native speaker. Not so that it becomes cumbersome to the frequency, but we can get ride reports, ask if we can go direct, get answers to odd request; any kind of clarification that we need gets answered. We know that we're communicating with each other.}

\section{U.S. Controllers Do Not Use ICAO Terminology}

My experience has been that the U.S. does not use ICAO terminology, ${ }^{6}$ even with German, French, or Chinese pilots. It's a mistake, in my humble opinion, and I think they should. But those who understand its usage know what I mean when I say, "I've got them established on the localizer to twenty-two left." Interviewer: And this is only in the U.S., not others? Yes, because even Canada uses ICAO terminology now.

\section{Frequently Explanation}

Of the nine pilots who indicated that "Between $25-74 \%$ of my interactions with controllers" involved Common English, 56\% provided comments.

\section{It Is Easier to Communicate in Your Native Language}

We get colloquial in the U.S. because we have that common understanding. After the initial clearance, we'll ask for other stuff and it's frequently in Common English. It's just easier to communicate in your native tongue. I think that's why, internationally, controllers sometimes switch to their native language-it's quicker and easier. Then they switch back because Common English may be slower and not as efficient to them.

\section{Occasionally Explanation}

Nineteen pilots indicated that during routine communications, "Between 10-24\% of my interactions with controllers" involved Common English. When interviewed, approximately $58 \%$ made comments.

\section{"Enter the Hold" and "Miles to Run"}

There is more "banter" in the native English system than foreign systems. We use Common English to convey non-standard things. I use the British example of enter the hold. Hong Kong has something that's unique. When you first check in and are very close to landing, they'll say, "Forty-five track miles to run," telling us that's the linear distance we have before touching down.

\footnotetext{
${ }^{6}$ May mean phraseology—aviation terminology covers a large territory
}

Interviewer: Do we need that kind of phraseology adapted to the U.S.?

I'd like it, and it would be a good thing to know. But I keep coming back to the Newark area for the vectoring. We'd have to add the turns and the holding pattern.

\section{"Ride Reports" and "General Weather"}

Ride reports and weather are usually outside standard phraseology, so we'll have more communication about them in Common English.

\section{Used With Domestic Carriers Only}

I'll hear [Common English] usually with domestic traffic. I can understand what is being said since it's in English. But, I hear more common jargon and non-standard phraseology with domestic air traffic than international arrivals.

\section{U.S. Uses Common English More Than U.K., Canada, or Australia}

To me, controllers in the U.K., Canada, and Australia use standard terminology more frequently than [controllers] in the U.S. Our controllers slip into conversational English.

\section{Rarely Explanation}

Only two of the five pilots who said "Less than 10\% of my interactions with controllers" included Common English. They limited their responses to interactions with controllers while on the airport surface areas.

\section{No Time for Common English}

Controllers strive more towards ICAO standard than pilots do. I would characterize that specifically when we are in line in airport areas. There's not much time for Common English. I'm busy and the controllers pretty much deal with you and get you out of there.

53. When flying in a native English-speaking country, how wouldyou describe the controllers'ability to communicate with you in Common English?

As shown in Table 8, 47\% of the pilots said the controllers' Common English communications skills were good, and another $53 \%$ said it was excellent. Their comments from questionnaires and interviews were organized according to their response selection and then common themes.

\section{Their Communication Skills Are Excellent Explanation}

About 24\% of the pilots who selected "Their communication skills are excellent" commented. 
Table 8. How Well Native English-Speaking Controllers Communicate in Common English.

\begin{tabular}{|l|c|c|l|}
\hline \multicolumn{1}{|c|}{ Alternative } & $\begin{array}{c}\text { Number } \\
\text { of Pilots }\end{array}$ & $\%$ & \multicolumn{1}{|c|}{ Issues } \\
\hline Their communication skills are excellent & 25 & 53 & Better Pronunciation and No Local Idioms It's Perfect \\
\hline Their communication skills are good & 23 & 47 & $\begin{array}{l}\text { Accents, Speech Rate, and Terms Can Make It } \\
\text { Difficult }\end{array}$ \\
\hline Their communication skills are only fair & 0 & 0 & \\
\hline Their communication skills are poor & 0 & 0 & \\
\hline Their communication skills are terrible & 0 & 0 & \\
\hline
\end{tabular}

Table 9. Pilot Attention Used When Native English-Speaking Controllers Talk to Them.

\begin{tabular}{|l|c|c|l|}
\hline \multicolumn{1}{|c|}{ Amount of Attention Used } & $\begin{array}{c}\text { Number } \\
\text { of Pilots }\end{array}$ & $\%$ & \multicolumn{1}{c|}{ Issues } \\
\hline A great amount & 0 & 0 & \\
\hline A considerable amount & 2 & 4 & Some Dialects Are More Difficult Than Others \\
\hline A moderate amount & 7 & 15 & $\begin{array}{l}\text { East and West Coast Talk Fast Leaving Us No Time to } \\
\text { Respond } \\
\text { Hong Kong, U.S. No Problem - U.K. Some Difficulty }\end{array}$ \\
\hline A limited amount & 25 & 52 & Some Accents and Communication Need More Attention \\
\hline It is effortless & 13 & 27 & $\begin{array}{l}\text { New York Gives Too Many Instructions but It's Native } \\
\text { English }\end{array}$ \\
\hline A limited amount/It is effortless & 1 & 2 & U.S. Is Effortless - Elsewhere It Takes a Limited Amount \\
\hline
\end{tabular}

With Better Pronunciation and No Local Idioms It's Perfect

I've found controllers' accents or pronunciations differ. but their skills are excellent. Typically, they stay fairly standard so they don't use Common English much. If they do, it's in a clear, concise, and correct tempo. To me, familiarity with the accent is key and the more I'm familiar with it, the easier it is to understand.

Their Communication Skills Are Good Explanation

Among the pilots who selected "Their communication skills are good," $52 \%$ provided comments.

\section{Different Accents, Speech Rate, and Terms Can Make It Difficult}

In my flying experience, North American English is different from other types of English. In some countries, sometimes I can't understand Common English because of the accent. Also, I've found differences in local terms - in the U.K., it's lift and in the U.S. it's elevator. But any misunderstandings can be cleared up quickly.

53a. In general, how much attention do you have to use to make sense of what the native English-speaking controller is saying?

The data in Table 9 indicate that $52 \%$ of the pilots said a limited amount of their attention was used to understand what native English-speaking controllers said, while $27 \%$ said it was effortless. There were nine pilots who thought otherwise. For them, either moderate or considerable attention was used.

\section{A Considerable Amount Explanation}

Although there were two pilots who selected this response, only one provided comments.

\section{Some Dialects Are More Difficult Than Others}

The British dialect is extremely hard for me to understand. I focus $100 \%$ of my attention to make sure I understand what they're saying. But even in the U.S., I have a hard time understanding some native English controllers.

\section{A Moderate Amount Explanation}

Seventy-one percent of the pilots offered comments. One pilot in this group said his difficulty resided in being relatively new to international operations and his unfamiliarity with different dialects and languages.

\section{East and West Coast Talk Fast Leaving Us No Time to Respond}

Sometimes the fast pace coupled with the speed of talk and accent, leaves me with no time to respond. They're busy and we're busy running checklists, depending on what phase of [flight] we're in. Sometimes we all forget how busy the other person is.

\section{Hong Kong, U.S. No Problem-Scotland and London Some Difficulty}

There's a comfort level being in an English-speaking country, but we still have to be very cautious because the procedures can vary quite a bit from what we do in the U.S. We can't let that comfort level overtake us so we become complacent. Going into Hong Kong, is clear as a bell for me. In Scotland, I have to listen very closely. Sometimes I have a hard time with the Australian accent and my understanding suffers. 
Table 10. Most Troubling Language-Based Problems With Native English-Speaking Controllers.

\begin{tabular}{|l|l|}
\hline \multicolumn{1}{|c|}{ Language-based Problems } & \multicolumn{1}{c|}{ Issues } \\
\hline Amount of Information (6) & Too complex clearances (1) Too many instructions (5) \\
\hline Delivery Technique (22) & Clipped transmissions (2), Speech rate (11), Tempo (9) \\
\hline Interpreting Message Content (10) & Non-ICAO (3), Non-Standard Phraseology (4), Slang (2), Syntax (1) \\
\hline Speech Quality (20) & Dialect (2), Accent (11), Pronunciation (5), Pitch (2) \\
\hline
\end{tabular}

Interviewer: Is it comparable, problematic, or easier in the U.S. going from the East Coast to the West Coast and from the North to the South?

For me, there are areas that are more problematic. It takes me a longer to get used to controllers in Atlanta and Jacksonville because I grew up in New York. There's a little bit of a difference, but not the marked one between Hong Kong and London controllers. We don't have the big differences in the U.S. that we do overseas.

\section{A Limited Amount Explanation}

Of the 25 pilots who reported a limited amount of attention was used, $28 \%$ made comments.

\section{Some Accents and Communication Need More Attention}

In my experience, even with all the different English accents, misunderstandings can be cleared up quickly. Sometimes controllers speak so fast I can't understand everything. And, the English controllers say, "Maintain radar heading," "Report ready for descent," or other commands a little differently than what I hear in the States. Occasionally, I have to pay more attention and ask, "What was that?" We talk to the same controllers all the time, so it's not that big a deal.

\section{It Is Effortless Explanation}

Two of the 10 respondents made comments regarding their experiences in the U.S. There was one additional pilot who qualified his selection by noting that although there are regional differences in the U.S., it is what he is used to and that makes it effortless. However, once outside the U.S., it does take a limited amount of attention because of unfamiliarity with local idioms.

\section{New York Will Give You Six Instructions at Once but It's Native English}

Native English is second nature to us, but there is always caution when I'm listening. My experience is that some U.S. controllers tend to give a heading, altitude change, airspeed, and a transponder change pretty much in the same transmission; it gets "lost in the sauce." But, they are trying to put 10 pounds of stuff into a five-pound bag.

\section{3b. What are the most troublinglanguage-based problems you experience with native English-speaking controllers?}

Forty-two pilots generated a list of 58 items that were compiled into 13 issues. The number in the parentheses presented in Table 10 indicates how often it was reported by the pilots. Table 10 further shows these issues to be grouped into four themes: Amount of Information, Delivery Technique, Interpreting Message Content, and Speech Quality. Delivery Technique represents 38\% of the items, while Speech Quality represents another 34\%. Another 17\% appear in Interpreting Message Content and the remaining 10\% in Amount of Information (allowing for rounding error). During the interviews, $40 \%$ of these pilots commented.

Since accent, dialect, and pronunciation have already been covered in detail, there is no need to discuss them further. Two pilots expressed difficultly understanding higher-pitched controllers. For them, higher-pitched voice interfered with radio reception and voice quality over the speakers on the flight deck.

\section{Amount of Information}

Conveying complex clearances or instructions are problems for me. Quite often controllers give me too many in one sentence, "Climb to two two zero, heading one eight zero, slow to two ten and proceed to GIPSO." I have to stop and say, "What?" My mind doesn't work that fast. We're talking about the run-ons-more than three at a time.

\section{Delivery Technique}

I find that controllers either talk too fast or too slow. It doesn't matter to me what language controllers' speak-if they're real busy, it's hard to get a word in edgewise. I can't digest and understand instructions as fast as they can speak them. Other language-based problems are clipped speech or clipped words.

Interviewer: When you say "clipping," is that an unintentional clip or is it due to technique?

I think it's both. Some Latin America controllers have a Calypso rhythm to their speech so it sounds continuous to me. It's related to emphasizing a second syllable so it gets clipped off. I don't know if they use a foot-operated mic, but that's a problem, too.

\section{Interpreting Message Content}

The most troubling language problems I have with native English-speaking controllers are procedural issues, local knowledge, and not realizing that there might be changes from Standard English operations that I would expect domestically. Some things can't be said with a pat, standard phraseology. Like, "We need you to fly this much of the route, but then we need to divert you because we have a storm over here, then we need you to re-intercept." That's when I need to think a little bit more, regardless of language. 
Table 11. How Frequently Pilots Heard Jargon or Slang That Was Difficult to Interpret.

\begin{tabular}{|c|c|c|}
\hline How Often Interpretation was Difficult & $\begin{array}{l}\text { Number } \\
\text { of Pilots }\end{array}$ & Issues \\
\hline $\begin{array}{l}\text { Rarely } \\
\text { (<10\% of my time monitoring communication) }\end{array}$ & 43 & $\begin{array}{l}\text { There Is Slang/Jargon but It's Easily } \\
\text { Interpreted } \\
\text { American Slang/Jargon Is a Problem for } \\
\text { Foreign Carriers }\end{array}$ \\
\hline $\begin{array}{l}\text { Occasionally } \\
\text { (10-24\% of my time monitoring communication) }\end{array}$ & 3 & \\
\hline $\begin{array}{l}\text { Frequently } \\
\text { (25-74\% of my time monitoring communication) }\end{array}$ & 1 & Follow the "Guppy" or the "Barbie Jet ${ }_{a}$ " \\
\hline $\begin{array}{l}\text { Often } \\
\text { ( } 75-90 \% \text { of my time monitoring communication) }\end{array}$ & 1 & $\begin{array}{l}\text { It's Take the Scenic Taxi in Chicago and JFK } \\
\text { It's the Penalty Box in Miami }\end{array}$ \\
\hline $\begin{array}{l}\text { Without fail } \\
\text { (>90\% of my time monitoring communication) }\end{array}$ & 0 & \\
\hline
\end{tabular}

${ }^{a}$ Neither of these is jargon or slang but legitimate names of aircraft.

Native English-speaking controllers outside the U.S. use ICAO phraseology, and it is somewhat different from American ATC phraseology. ${ }^{7}$ When I am cleared by an Irish controller first thing in the morning, he might say, "Route direct to LITHY." Will our route take us direct to LITHY, [or] are we supposed to go present position direct LITHY? We learn that route direct means present position direct.

Procedurally, local jargon or slang can be difficult to interpret. We don't notice it because we're used to it in the States. For example, "Scoot across the runway real quick for me." We hear an MD 88 called a Mad Dog. If a Lufthansa pilot is told, "Follow the second Mad Dog," he might not understand what the controller wants. Does that mean anything to him? Are they used to that terminology? If a controller told a pilot, "Give me a good time," would the pilot know "give me a good time" means increase your speed?

\section{3c. How often have you heard native English-speaking con- trollers use jargon or slang that was difficult to interpret?}

There might have been some confusion concerning the phrase "difficult to interpret." None of the pilots indicated that any slang/jargon heard was difficult to interpret, although unfamiliar terms, aircraft names, etc., are mentioned as slang/jargon. Their responses to the interviewers' questions and compiled comments from the written and interview portions of the questionnaire are included below.

As seen in Table 11, among the pilots who selected "Occasionally," "Frequently," and "Often," one pilot in each group offered comments. One said, "It's not very hard to understand," while the other said that foreign pilots probably would not know what either a "Guppy" or "Barbie Jet" was. ${ }^{8}$ The pilot who selected "Often" said that controllers who deliver taxi clearances around Chicago and JFK use some slang/jargon.

\footnotetext{
${ }^{7}$ Federal Aviation Administration (2010b).

${ }^{8}$ While this may be true, in the U.S. the controller may use type, model, or manufacturer's name.
}

\section{Rarely Explanation}

Approximately $18 \%$ of the pilots who selected rarely provided comments.

\section{There is Slang/Jargon but It's Easily Interpreted}

The only slang I've ever gotten had to do with aircraft movement and unclear direction- "Just go around this guy." It doesn't seem to really relate once airborne.

Expect a slam dunk. ATC's telling us that we need to do something; what that something is depends on where we are. And that's a judgment call.

Interviewer: Some pilots said the use of pleasantries is a waste of airtime. Is there any verbiage you can do without from the controllers?

No, I disagree with that. First of all, I'm building a bit of a rapport, should I need something. Second, since we're human beings, we like to treat each other with some amount of respect, and that's the way to do it on the radio.

That comes back to the fundamental point that we were talking about earlier-communicating ideas, whether through the use of standard language or not. The problem for me is digging through the pronunciation to understand what word was just used. The whole essence of communication is having a concept of what we want, what the controller wants us to do, and communicating that to each other is not generally an issue once we get past the issue of the language.

\section{American Slang/Jargon Is a Problem for Foreign Carriers}

U.S. controllers use jargon all the time- - but is it difficult to interpret? They'll say I'm going to have to snug up on this guy over here-what's that? Some foreign pilots are going to have a hard time understanding what this expression means. When we go overseas, controllers very rarely use that kind of jargon. It's hard enough for [U.S. pilots] to understand regular English. So it's a little unfair. 
53ci. The respondents' examples of jargon that were difficult to interpret were "Guppy" and "Barbie Jet."

Each term refers to a particular aircraft. The "Guppy" is in reference to the Boeing 737 aircraft, while the "Barbie Jet" refers to Canadair Regional Jet (CRJ) series 200/700/900. The Guppy series reference the manufacturer's names for the C-97 aircraft that was modified to carry large cargo, primarily rockets for NASA. It includes the "Mini Guppy," "Super Guppy," and "Pregnant Guppy." The term "Barbie Jet" is used in advertisements for Canadair Regional Jets. Another term mentioned at different parts of the focus group discussions was "Mad Dog," referring to the McDonnell Douglas aircraft manufacturer.

\section{3cii. The respondents did not list any examples of slang that was difficult to interpret.}

\section{DISCUSSION}

This report focuses on communications between native English-speaking controllers and how well they communicate with native English-speaking pilots. It provides an overall perception among 48 U.S. ATP pilots of how these communication exchanges affect safety, the communication process, workload, and situational awareness. The interviewers took the pilots' comments and opinions at face value, occasionally asked additional questions, but did not challenge any of their statements or comments.

\section{Language Experiences in Native English-Speaking Airspace/Airports}

The pilots reported hearing 17 different dialects of English during their flights to countries in Asia, Europe, North America, and Oceania. Of these dialects, British English, North American English, and Hong Kong English were the top three listed by the U.S. pilots.

When asked how they would rate their overall native English-speaking language experiences during these flights, $35 \%$ gave it a very positive rating, while $44 \%$ said it was positive. The one pilot who gave a negative rating did so because the he had some difficulty understanding what the controller was saying.

\section{Effects of Native English-Speaking Language Differences on Pilot Workload}

When asked how hearing English spoken by a native speaker affected their workload, 9\% said that there was a decrease, $17 \%$ reported no change, $63 \%$ said there was only a minimal or slight increase, and $11 \%$ said it increased. Among the pilots who reported a slight or minimal increase, factors that contributed to workload included a tendency for more relaxed radio discipline (more pleasantries, slang) and faster speech rate-especially with increases in traffic volume. When combined with poor radio quality, they might have to listen more closely to ensure they heard correctly the first time-especially if there was a new crewmember on the flight deck unfamiliar with the local accent and dialect. This also held true among the pilots who experienced increased workloads. For them, two factors came into play: Some English dialects require them to listen more closely to what is said and also to what the words mean in that locale.

\section{Frequency of Communication Problems}

When asked how often they experienced communication problems, $94 \%$ of the pilots reported that it occurred in fewer than $25 \%$ of their interactions with controllers. If they did have a problem, it was corrected easily because English was the native language they had in common. Generally, communication problems occurred for two reasons: First, there were times when the pilots could not decipher what was said because the clearances were given faster than they could process them, and second, they had a harder time understanding the names of fixes and waypoints because of regional dialects and variations in pronunciation. The pilots who experienced communication problems to a greater extent named the geographical areas where they were likely to encounter them but did not specify the types of problems or their root causes.

\section{Variability in English Language Skills of Pilots and Controllers}

When asked whether English language skills were comparable from one native English-speaking country/ airport to that of another, $83 \%$ of the pilots reported that the pilots and controllers were comparable, and $17 \%$ said they differed. The pilots shared several common threads in their comments. The four more notable perceptions are (a) controllers seem to have less of an accent than pilots do; (b) regardless of aircraft registry, once an air carrier left its homeland and entered foreign airspace, pilots have difficulty understanding clearances and need to have them repeated several times; (c) regardless of country, some controllers seem to be less tolerant of pilots who ask for repetition, clarification, or verification of a previous transmission; and (d) some dialects are more difficult to understand and add workload for the pilot and controller.

\section{Factors Contributing to the Intelligibility of Native English-Speaking Controllers}

Nearly $75 \%$ of the pilots said they used extra effort when listening to some native English-speaking controllers. Some controllers are generally more difficult for the pilots to understand because of variations in dialects at very busy international airports. Notably, the English spoken by pilots and controllers in the U.K. and the U.S. were discussed because of their regional distinctions. In particular, were the accents of Irish, Scottish, and Welsh controllers, as well as those used by U.S. controllers in Atlanta, Boston, Chicago, and New York. In addition to accents, the pilots also said that differences in how words were pronounced (especially waypoints and fixes), jargon (e.g., go fast), and a rapid speech rate all contributed to the intelligibility of the controller. 
There were pilots who said they did not have to work harder to understand controllers. Although they heard regional differences, for them the effects were insignificant.

\section{Factors Contributing to the Understandability of Native English-Speaking Controllers}

The ability to understand controllers involved pronunciation, speech rate, and accent, ${ }^{9}$ followed by pitch, expectation, intonation, and phraseology. Some accents were easier to understand, while the ones unfamiliar to the pilots were said to be more difficult. Likewise with intonation, because it provides the emphasis, tone, and variety in oral languages that can alter meaning by simply modulating pitch and loudness while speaking. As speakers, we use these cues to signal a question (raised pitch at the end of a sentence) or the end of a sentence (less volume). Slight shifts in intonation can be used to judge the mood of the speaker or lead the listener to infer sarcasm. Different English dialects have different intonation patterns that can influence how well listeners understand what is being said. These melodies of speech are learned during infancy.

Air traffic control telephony consists of a standard phraseology that controllers repeat throughout their workday. Rarely should they deviate from that standard. However, there are differences among countries about the phraseology they consider standard. When pilots and controllers do not understand each other due to these differences, coupled with variability in delivery technique, inevitably one or the other will make a request for repetition, confirmation, or verification, resulting in increased workload and radio frequency congestion. Generally, normal conversational speech occurs at about 160 words per minute (wpm) and depends, in part, on the number and duration of pauses and syllables. The greater they are in number and duration, the slower the speakers' rate of speech when measured by words per minute (Utterback, 2000).

In a study of fluency, Cauldwell (2007) examined the speech rate of a controller and four pilots at an airport in Frankfurt from a Tower recording. For that analysis, individual transmissions were parsed into speech units, and the number of words spoken per minute was derived to be $190 \mathrm{wpm}$ for that controller and $150 \mathrm{wpm}$ for the pilots. Although \$5.2.1.5.3 (ICAO, 20011) states that pilots "should maintain an even rate of speech not exceeding 100 words per minute," and FAA Order 7110.10T Flight Services \$2-1 states, "When weather and flight information shall be broadcast/recorded ... data shall be spoken at a rate of 100 to 120 words-per-minute," there is no guidance for controllers when in direct communications with pilots as to what the preferred rate of speech should be.

\section{ICAO Standard Phraseology Usage by Native English-Speaking Controllers}

Pilots reported that native English-speaking controllers use ICAO phraseology in at least $75 \%$ of their routine communications. They also noted that controllers in the U.S. are more prone to deviate from ICAO and use "Americanisms." They would like to see the U.S. adopt the ICAO standard.

\section{Common English Usage by Controllers in Native English-Speaking Countries and Their Ability to Communicate in Common English}

Pilots were very positive about the controllers' use of Common English. In fact, 99\% of them reported the controllers had either good (47\%) or excellent (52\%) communication skills. Moreover, Common English occurred in varying degrees as they gained familiarity with each other because of their common flight/work schedules. Once they recognized each others' voice and because they shared a common language, requests, verifications, and confirmations might become more relaxed and conversational while still maintaining professionalism. They also used Common English when ICAO standard phraseology did not work. In the U.S., a standard phraseology was never constructed for non-standard events because English language proficiency was not considered an issue. It was assumed that the pilot and controller would resolve the problem using Common English. ${ }^{10}$

\section{Amount of Attention Required for Understanding}

Just because someone is easily understood does not presuppose that the listener does not have to pay attention to what is being said. In fact, the pilots differed in the amount of attention they allocated to understanding. It did not seem to matter whether or not the pilot was flying in different regions of the U.S. or in other Englishspeaking countries; their differences in opinion were based on their familiarity with the controller's accent, the local dialect, and the pace they and controllers operate under (especially on a descent to the airport when traffic is heavy or weather conditions are less than optimal).

When the fast pace marries up with individual differences in accent, dialect, and speech rate, pilots pay more attention, especially if there are procedural differences they must be aware of. For example, a pilot from New York may have some problems understanding controllers from Georgia or Florida, as would a pilot from Texas flying into Hong Kong or London. Nonetheless, there is a comfort level knowing that controllers have good-to-excellent communication skills and that their understanding of the English language will not undermine safety of flight.

\footnotetext{
${ }^{9}$ www.soundcomparisons.com is a Web site where you can listen to and compare how the same 110 words are pronounced in 50 English accents.
}

\footnotetext{
${ }^{10}$ Conversation between the first author and a recent FAA retiree of the former Air Traffic Systems Requirements Service.
} 


\section{The Most Troubling Language-Based Problems}

The pilots were very open to discussing the languagebased problems they experienced. For them, many of the problems centered on controllers transmitting lengthy and complex clearances that contained more information than they could process reasonably in the amount of time used by the controller to deliver it-especially if spoken by a controller with a high-pitched voice over the aircraft's radio equipment. They also spent a considerable amount of time talking about the contents of an ATC message.

\section{Amount of Information}

A common comment from the pilots was that their minds could not process the amount of information transmitted in one message fast enough to understand what they were to do. The following example was given by a pilot: "Climb to two two zero, heading one eight zero, slow up to two ten, and proceed to GIPSO." There is much research that shows that both message length and complexity affect readback error (RBE) rate. In particular, field and simulation findings (see Prinzo \& Britton, 1993 for a review of the literature; Cardosi Brett, \& Han, 1996; and Morrow \& Prinzo, 1999) led to the recommendation that controllers should transmit less information more often. Recently Prinzo, Hendrix, and Hendrix (2006) found that both the number of pilot requests and readback errors increased as the complexity and number of aviation topics in terminal radar approach control ATC messages increased - especially when pilots were performing approach, as compared with departure tasks. Messages with one instruction resulted in a $3.84 \%$ RBE rate, while those with four instructions had a $25.7 \%$ RBE rate. A similar pattern emerged for the amount of information in a message-messages with a low complexity value resulted in 2-6\% RBE rate; messages with high complexity values had a 35\% RBE rate. A comparable analysis (Prinzo et al., 2009) performed on en route voice tapes further revealed that message complexity only affected readback errors involving the omission of information, while longer messages led to substitution and transposition errors. Among their recommendations were that no more than three instructions appear in any ATC transmission, and route clearances are given as stand-alone transmissions.

\section{Delivery Technique}

As mentioned earlier, pilots encounter difficultly with fast rates of speech. Although ICAO recommends pilots speak at a rate of $100 \mathrm{wpm}$, there is no such recommendation for controllers. As pointed out by Cauldwell (2007), 100 wpm might be too slow among the more fluent speakers of English. In fact, one pilot in this study mentioned the drawl of some Southern controllers when delivering clearances as being slow. Together, these findings suggest there might be circumstances where native speakers of English with different dialects might have difficulty understanding each other-such as an Asian
Indian speaker of English talking with a Texan who speaks American English, whereas those with the same dialect may want to communicate at a faster rate of speech.

\section{Message Contents}

The most troubling language barrier problems with native English-speaking controllers are procedural issues, local knowledge, and not realizing that there might be differences between international and domestic ATC phraseology. The pilots provided examples of these differences - "line up and wait" compared to "taxi into position and hold," "stand 15" compared to "gate 15," and "route direct" compared to "present position direct."

\section{Slang or Jargon Usage by Controllers}

Since there is a common language among the various English dialects, none of the U.S. pilots reported problems with any particular local slang or jargon. Slang, like idioms, appears in conversational speech and can be difficult for listeners who are unfamiliar with local expressions (or history) to understand, but they can work through them because of the common root language. Phrases such as "scoot across the runway real quick for me," "give me a good time," "follow the Mad Dog," were some examples cited. Together with local jargon (e.g., "expect a slam dunk"), these types of messages can lead to communication problems, especially among non-native English-speaking pilots and pilots unfamiliar with the local use of slang, jargon, and idioms. These expressions should be discouraged because they will diminish situational awareness among less proficient pilots.

Unlike everyday conversations, air traffic control communication must be held to a higher standard. Its words must be precise in definition, subsequent actions predictable, and outcomes transparent to the observer. When messages are transmitted, they should be held to a standard in broadcast technique as defined by ICAO and its membership.

\section{Recommendations}

1. Adopt a standard dialect for use in ATC communications. Just as radio and television news broadcasters learn to speak using a nondescript accent, actors often hire language coaches to teach them the "standard Hollywood accent" to portray geographically neutral characters.

2. All trainees and current certified professional controllers must successfully complete an English language course in voice and articulation. In addition to instruction in the principles of voice production and articulation of speech sounds, they will receive training in loudness, speech rate, pitch, articulation, enunciation, and pronunciation for ATC communication.

3. Define an optimal rate of speech for use by air traffic controllers when in communication with pilots. This could be derived by extracting the number of words per minute spoken by controllers that did not result in 
a request for repeat, clarification, or verification from pilots. It may be that a different speech rate should be used with pilots who are not native speakers of English. Research is needed to provide guidance on the optimal rate of speech for different populations of speakers.

4. Develop new standard phraseology for non-routine events. Generally, the controller needs to have the pilot answer one question, "What do you need from me?" Based on the pilot's response, the controller would coordinate the appropriate ground actions to provide the pilot with what is needed. This phraseology could be provided as part of the DataCom message set. It could include a list from which the pilot could select the necessary items such as, "Divert to Similar Airport With Hospital," "Fire Rescue," "Ambulance," "Police," and so on.

5. Controllers should be discouraged from using local jargon, slang, idiomatic expressions, and other forms of conversational communications when transmitting messages to pilots. Although colorful and fun, they have no place in air traffic control and diminish situational awareness, can lead to requests for repeat, and otherwise disrupt information transfer.

\section{REFERENCES}

Cardosi, K., Brett, B., \& Han, S. (1996). An analysis of TRACON (Terminal Radar Approach Control) controller-pilot voice communications. (Report no. DOT/FAA/AR-96/66). Washington, DC: Department of Transportation.

Cassidy, F.G. \& Hall, J.H. (1991). Dictionary of American regional English, Vol. 2, D-H. Cambridge, MA: Harvard University Press. p.55. Retrieved from books.google.com/books?id=vAr2T4Bh7nkC\&p $\mathrm{g}=\mathrm{PA} 55 \& \mathrm{dq}=\mathrm{devil}+$ strip. Accessed 50 Mar 2010.

Cauldwell, R.T. (2007). Defining fluency for air traffic control. Speak Out!!1, 37, 10-16. http:// www.speechinaction.net/SPARC_Richards_ publications.htm Accessed 20 July 2010.

Federal Aviation Administration (Feb 2010a). FAA Order 7110.10U Flight Services. Washington, DC: Author. Retrieved from http://www.faa.gov/document Library/media/Order/7110.10UBasic.pdf. Accessed 20 July 2010.

Federal Aviation Administration (Feb 2010b). Order 7110.65 The handbook of air traffic control. Washington, DC: Author. Retrieved from http://www. faa.gov/documentLibrary/media/Order/ATC.pdf. Accessed 20 July 2010.

International Civil Aviation Organization (2001). Annex $10 \mathrm{Vol}$. II (6th ed.)-Aeronautical telecommunications-(Communication procedures including those with PANS status). Montreal, Canada: Author.

International Civil Aviation Organization (2004). Manual on the implementation of ICAO Language Proficiency Requirements. Doc 9835/AN453. Montreal, Quebec, Canada: Author.

Leverett, T. (2007, May). Dialects in a changing language. Global Study Magazine 4(3), 56-57. http:// globalstudymagazine.com/site/articles/359. Accessed 20 July 2010.

Morrow, D. \& Prinzo, O.V. (1999). Improving pilot/ATC voice communication in general aviation. (Report no. DOT/FAA/AM-99/21). Washington, DC: Federal Aviation Administration..

Prinzo, O.V., \& Britton, T.W. (1993). ATC/Pilot voice communications: A survey of the literature. (Report no. DOT/FAA/AM-93/20). Washington, DC: Federal Aviation Administration.

\footnotetext{
${ }^{11}$ Speak Out! Published by the International Association of Teachers of English as a Foreign Language (IATEFL).
} 
Prinzo, O.V. \& Campbell, A. (2008). A. U.S. airline transport pilot international flight language experiences report 1: Background information, general/preflight preparation and generallair traffic control (ATC) procedures. (Report no. DOT/FAA/AM-08/18). Washington, DC: Federal Aviation Administration.

Prinzo, O.V., \& Thomson, A.C. (2009). The ICAO English language proficiency rating scale applied to enroute voice communication of U.S. and foreign pilots. (Report no. DOT/FAA/AM-09/10). Washington, DC: Federal Aviation Administration.

Prinzo, O.V., Hendrix, A.M., \& Hendrix, R. (2006). The outcome of ATC message complexity on pilot readback performance. (Report no. DOT/FAA/AM-06/25). Washington, DC: Federal Aviation Administration.

Prinzo, O.V., Hendrix, A.M., \& Hendrix, R. (2009). The outcome of ATC message length and complexity on en route pilot readback performance. (Report no. DOT/FAA/AM-09/2). Washington, DC: Federal Aviation Administration.

Prinzo, O.V., Campbell, A., Hendrix, A.M., \& Hendrix, R. (2010a). U.S. airline transport pilot international flight language experiences report 2: Word meanings and pronunciation. (Report no. DOT/FAA/ AM-10/7). Washington, DC: Federal Aviation Administration.
Prinzo, O.V., Campbell, A., Hendrix, A.M., \& Hendrix, R. (2010b). U.S. airline transport pilotinternational flight language experiences report 3: Language experiences in non-native English-speaking airspacelairports. (Report no. DOT/FAA/AM-10/9). Washington, DC: Federal Aviation Administration.

Prinzo, O.V., Campbell, A., Hendrix, A.M., \& Hendrix, R. (2010c). U.S. airline transport pilot international flight language experiences report 4: Non-native English-speaking controllers communicating with native English-speaking pilots. (Report no.DOT/FAA/ AM-10/12). Washington, DC: Federal Aviation Administration.

Utterback, A.S. (2000). Broadcast voice handbook: How to improve your on-air delivery (3rd ed.). Chicago, IL: Bonus Books Inc.

Whitman, W. (1892). Slang in America. In Prose works. Philadelphia, PA: David McKay. 
